\begin{tabular}{ccc}
\hline International Journal of Engineering \& Technology, 7 (2.32) (2018) $459-461$ \\
SPC & Website: www.sciencepubco.com/index.php/IJET \\
Research paper & Technology \\
\hline
\end{tabular}

\title{
Extreme Power Point Tracking to Yield Maximum Power in Solar Grid System
}

\author{
D.Seshi Reddy ${ }^{1}$, G.S.S.Susmitha ${ }^{2}$, N.Yamini ${ }^{3}$, N.Yashwanth ${ }^{4}$ \\ ${ }^{1,2,3,4}$ Department of EEE, Koneru Lakshmaiah Education Foundation, Andhra Pradesh, India - 522502 \\ *Corresponding author E-mail: dseshireddy@kluniversity.in
}

\begin{abstract}
To minimize power losses by limiting maximum feed-in power in a PV system. By this, we can get a stable powergenerationoperation. There are currently two types of charge controllers commonly used in Solar PV grid connected power system, (i) PWM (pulse width modulation) \& MPPT (Maximum Power Point Tracking). Present solar inverter are not performing good yielding for wide range of irradiance and temperature. In this paper, MPPT adoption target to improve the performance when solar cell temperature varies from moderate to maximum from 450C to 750C. We used modified Perturb and Observation P\&O MPPT technique, because it modifies the operating voltage or current of PV panel until we get maximum power extraction at wide range of operating conditions. Another technique opted in this paper, PWM charge controller is a good low cost solution for small capacity inverters only. In DC - DC converter switching strategy such that optimizes charge distribution between the battery bank or utility grid. In this we use only voltage sensor at PV array along with irradiance and temperature inputs and same had simulated in MATLAb2017a environment. The results obtained are satisfactory with consistant performance for wide range of temperature.
\end{abstract}

Keywords: PWM, MPPT (P\&O), Grid connected PV system.

\section{Introduction}

Solar powered Energy is the outstanding amongst other Renewable Energy for future applications .So the utilization of Photo Voltaic (PV) frameworks expanded with decreased expenses and expanded effectiveness. In any case, the age of power from Photo Voltaic (PV) frameworks is more costly than the other nonRenewable Energy sources. We realize that non-customary sources which are otherwise called Renewable Energy assets are winding up more prevalent now a days as they are profit capable nature free. Sustainable power sources are characterized as the sources which can be recreated from nature over and over once even they utilized. There are numerous points of interest with Renewable Energy assets contrasting with non-sustainable power source. A portion of the favorable circumstances are Renewable Energy sources are taken a toll free and furthermore contamination free contrasted with non-sustainable assets. A portion of the primary cases for this Renewable Energy assets are sun based, wind, tidal and so forth. Here in this undertaking work we are thinking about Solar as the source and acquiring greatest power from the Sun by utilizing Maximum Power Point Tracking Algorithms (MPPT's). There are numerous calculations are utilized for removing greatest power, for example, annoy and watch, incremental conductance, fluffy control and so on. In our every day life, control electronic converters have been generally utilized, for industry applications as well as in numerous electronic items, for example, versatile gadgets and purchaser hardware. As a matter of fact, most electronic gadgets are not utilizing vitality straightforwardly from the pow-er framework or a battery set. To give the required voltage or current level to a heap, all in all, a power electronic converter is mediated between the power source and the heap to play out the transformation of the voltage or current level and notwithstanding control the power necessity. A regular power electronic converter is provided from a solitary information source, yet may give different yields. For the situation that at least two voltage or current levels are required by the heaps, a transformer with various yield windings is utilized [1], [2]. Then again, be that as it may, for a few applications, the heaps may not be controlled from a solitary source but rather from at least two info sources indicated by various voltage, current, and power appraisals [3-13]. For instance, a solar based road light is for the most part provided from solar cells, however needs a subordinate battery control.

\section{Solar System}

In photovoltaic (PV) system, solar powered cell is the fundamental segment. Figure 2 appears at a protection yield power trademark bends for the PV exhibit. It can be seen that a most extreme power point exists on each yield power trademark bend [5-8]. The Figure 3 demonstrates the (I-V) and (P-V) qualities of the PV exhibit at various sun oriented forces.

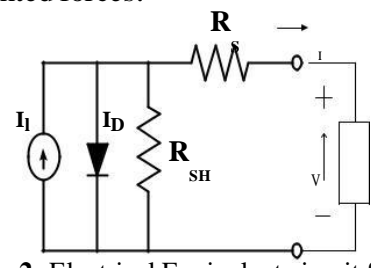

Figure 2: Electrical Equivalent circuit for PV Panel 


\section{Maximum Power Point Tracking (MPPT):}

It is an electronic system that operates PV modules in a manner to extract the maximum power from the system. Generally MPPT is installed between PV system and the load. Coupling to the load for maximum power transfer either providing a high voltage at lower current or lower voltage at higher currents.

\section{MPPT Techniques:}

a) Perturb and Observe (hill climbing method)

b) Incremental Conductance method

c) Fractional open circuit voltage

d) Fractional short circuit current

e) Neural networks

f) Fuzzy logic

\subsection{Perturb and Observe Method:}

Perturb \& Observe $(\mathrm{P} \& \mathrm{O})$ is that the simplest methodology. To sense the PV array voltage we tend to use one detector, that's the voltage detector so the price of implementation is a smaller amount and therefore straightforward to implement. The time complexness of this formula terribly|is extremelylis incredibly\} less however on reaching terribly near the MPP it doesn't stop at the MPP and keeps on worrisome on each the directions and this shows that the formula has reached very near the MPP and that we will set an applicable error limit or will use a wait perform that winds up increasing the time complexness of the formula. The speedy amendment of irradiation level doesn't appreciate (due to that MPPT amendments) and considers it as a change in MPP as a result of perturbation and winds up calculative the incorrect MPP.

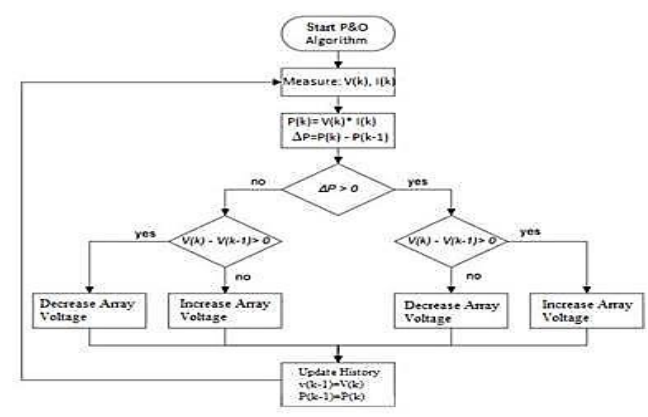

4.1 Flow chart of perturb \& observation

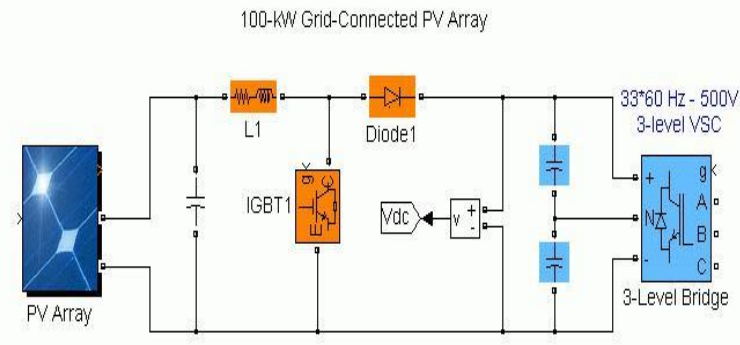

Figure 5: Single phase grid -connected PV system

\section{Parameters}

\begin{tabular}{|l|l|}
\hline Boost Converter Inductor & $\mathrm{L}=1.8 \mathrm{mH}$ \\
\hline PV-Side Capacitor & $\mathrm{Cpv}=1000 \mu \mathrm{F}$ \\
\hline DC Link Capacitor & $\mathrm{Cdc}=1100 \mu \mathrm{F}$ \\
\hline Switching Frequency Boost Converter & $\mathrm{fb}=16 \mathrm{kHz}$ \\
\hline
\end{tabular}

\begin{tabular}{|l|l|}
\hline \multirow{2}{*}{ DC-Link Voltage } & $\begin{array}{l}\text { Full bridge } \\
\text { inverter, inv }=8\end{array}$ \\
\hline Grid Nominal Voltage(RMS) & $\mathrm{fb}=16 \mathrm{kHz}$ \\
\cline { 2 - 2 } Grid Nominal Frequency & $\mathrm{Vdc}=450 \mathrm{~V}$ \\
\hline
\end{tabular}

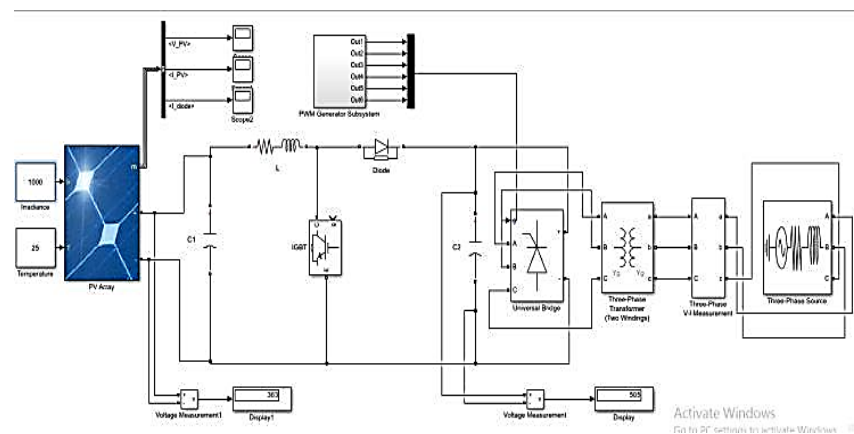

Figure 5.1-Simulink diagram of single phase grid connected $\mathrm{Pv}$ system

\section{Results}

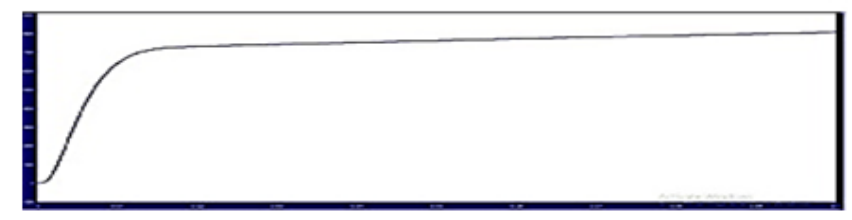

Figure 5.1.1-Voltage waveform

The above figure 5.1.1 simulation is voltage wave form at pv side

\section{Anti-Islanding Technique}

Islanding seems once some a part of the utility grid loses reference to the remainder of the system. This islanding will be intentional and unintentional. Islanding for PV power systems seems once the facility grid is tripped and also the electrical converter doesn't disconnect quickly enough and continues to control with the native load. during this paper, we tend to use ROCOF methodology, Under/Over Frequency/voltage methodology, DC-Link voltage methodology of islanding protection. this is often a passive methodology supported the native watching of the generator voltage undulation. And additionally to work out that Antiislanding detection is best for DC-Link voltage methodology in comparison to ROCOF methodology,Under/Over.Frequency/voltage methodology. These protection ways square measure cheap choices for islanding detection

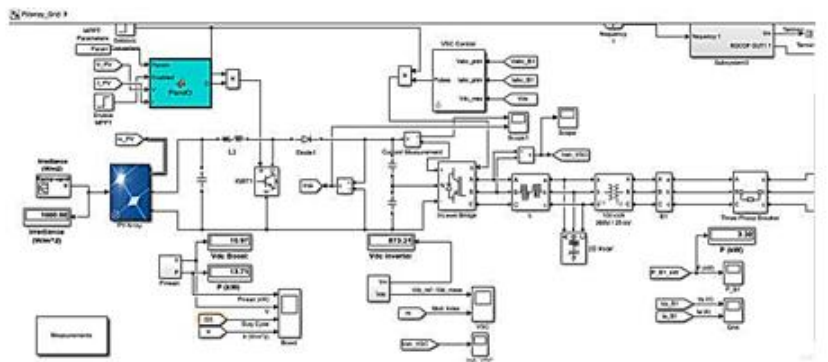

Figure 6.1- Detailed Simulink model of 100KW Grid-connected PV system Results:

In this case the proposed MPPT based Grid connected PV system is tested under anti islanding condition, the performance of the system is verified and the results shown below. 


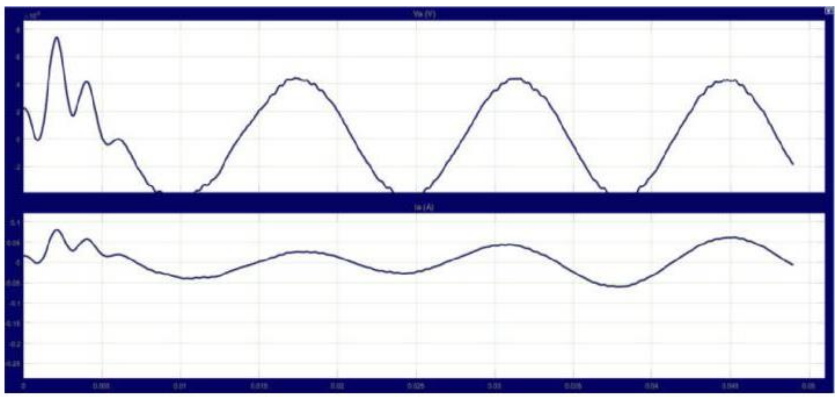

Figure 6.2 The above graph shows the voltage and current waveforms

The above figure 6.2 waveform is shows simulation result for voltage and current near the grid during fault.

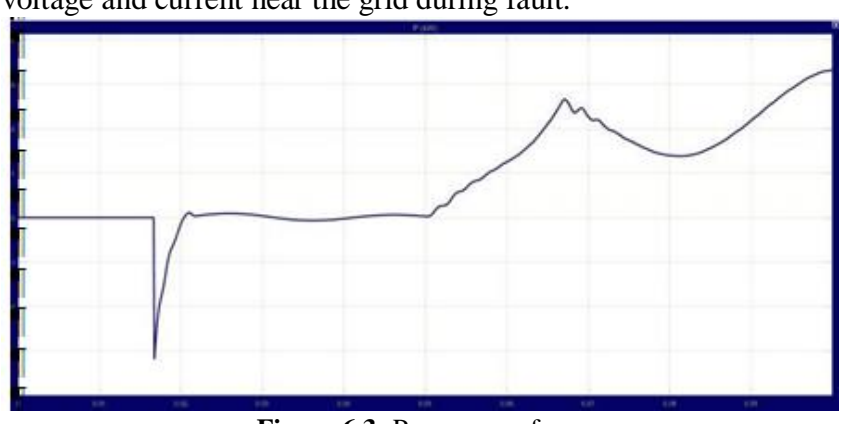

Figure 6.3- Power waveform

The active power obtained at grid PCC during the anti islanding mode of the PV system is shown in above simulation result.

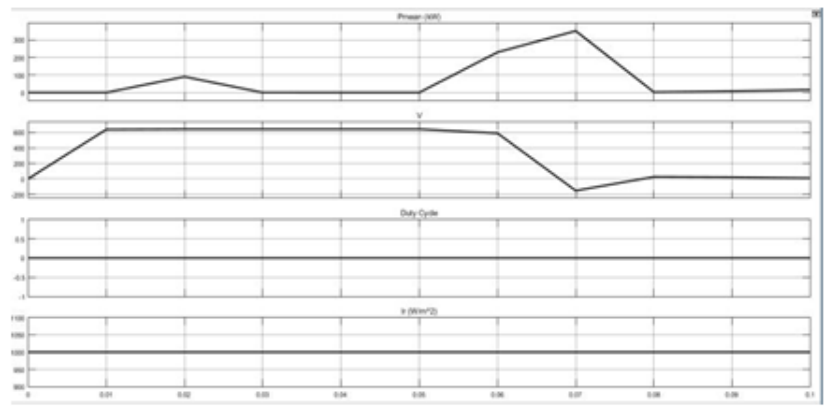

Figure 6.4 Wave forms for pmean,voltage,duty cycle,irradiation with respect to time

The DC link voltage of a boost converter and DC link power is shown in above summation result. The duty cycle required for the boost converter is generated by using the MPPT controller.

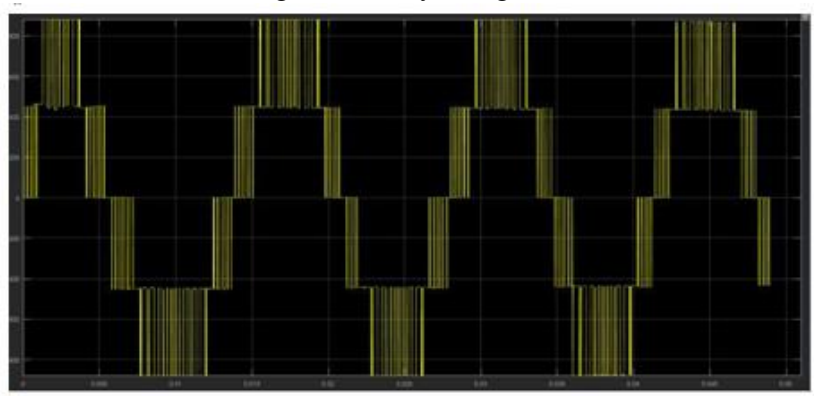

Figure 6.5-Wave forms of Vsc

The above simulation result shows the inverter output voltage obtained at 5-level voltage.

\section{Conclusion}

In this paper High-yielding power generation is done by limiting maximum feed-in power of pv system has been proposed. The proposed arrangement can guarantee a steady, consistent power age task. The proposed technique powers the PV system to work in favor of most extreme power point, in this way it can accomplish smooth advances. By using simulation results verified the effectiveness of the proposed control method in terms of reduced overshoots, minimized power losses.

\section{References}

[1] T. Stetz, F. Marten, and M. Braun, "Improved low voltage grid integration of photovoltaic systems in Germany," IEEE Trans. Sustain. Energy, vol. 4, no. 2, pp. 534-542, Apr. 2013.

[2] Ahmed, L. Ran, S. Moon, and J. -H. Park, "A fast PV power tracking control algorithm with reduced power mode," IEEE Trans. Energy Conversion, vol. 28, no. 3, pp. 565-575, Sept. 2013.

[3] Y. Yang, H. Wang, F. Blaabjerg, and T. Kerekes, "A hybrid power control concept for PV inverters with reduced thermal loading," IEEE Trans. Power Electron., vol. 29, no. 12, pp. 6271-6275, Dec. 2014.

[4] German Federal Law: Renewable Energy Sources Act (Gesetz fur den Vorrang Erneuerbarer Energien) BGB1, Std.,

[5] Energinet.dk, "Technical regulation 3.2.5 for wind power plants with a power output greater than $11 \mathrm{kw}$, , Tech. Rep., 2010.

[6] Y. Yang, F. Blaabjerg, and H. Wang, "Constant power generation of photovoltaic systems considering the distributed grid capacity," in Proc. of APEC, pp. 379-385, Mar. 2014.

[7] R. G. Wandhare and V. Agarwal, "Precise active and reactive power control of the PV-DGS integrated with weak grid to increase PV penetration," in Proc. of PVSC, pp. 3150-3155, Jun. 2014.

[8] W. Cao, Y. Ma, J. Wang, L. Yang, J. Wang, F. Wang, and L. M. Tolbert, "Two-stage PV inverter system emulator in converter based power grid emulation system," in Proc. of ECCE, pp. 4518 4525, Sept. 2013.

[9] Urtasun, P. Sanchis, and L. Marroyo, "Limiting the power generated by a photovoltaic system," in Proc. of SSD, pp. 1-6, Mar. 2013.

[10] S. B. Kjaer, J. K. Pedersen, and F. Blaabjerg, "A review of singlephase grid-connected inverters for photovoltaic modules," IEEE Trans. Ind. Appl., vol. 41, no. 5, pp. 1292-1306, Sept. 2005.

[11] F. Blaabjerg, R. Teodorescu, M. Liserre, and A. V. Timbus, "Overview of control and grid synchronization for distributed power generation systems," IEEE Trans. Ind. Electron., vol. 53, no. 5, pp. 1398-1409, Oct. 2006.

[12] B. Yang, W. Li, Y. Zhao, and X. He, "Design and analysis of a gridconnected photovoltaic power system," IEEE Trans. Power Electron., vol. 25, no. 4, pp. 992-1000, Apr. 2010.

[13] T. Esram and P. L. Chapman, "Comparison of photovoltaic array maximum power point tracking techniques," IEEE Trans. Energy Conversion, vol. 22, no. 2, pp. 439-449, Jun. 2007. 